Volume 1, Nomor 2, Maret 2021, hlm 51-58

BEMAS: JURNAL BERMASYARAKAT

p ISSN 27455866 | e ISSN 27457958

\title{
PELATIHAN PENGGUNAAN SOFTWARE MIND MASTER DALAM PENINGKATAN KUALITAS PEMBELAJARAN BAGI GURU DI SMAN 4 PURWOKERTO
}

\author{
Prayogo Hadi Sulistio ${ }^{1 *}$, Usep Muttaqin ${ }^{2}$, Aldi Aditya ${ }^{3}$ \\ ${ }^{1 *}$ Pendidikan Bahasa Inggris, Fakultas Ilmu Budaya, Universitas Jenderal Soedirman, Purwokerto, Indonesia \\ ${ }^{2}$ Sastra Inggris, Fakultas Ilmu Budaya, Universitas Jenderal Soedirman, Purwokerto, Indonesia \\ ${ }^{3}$ Sastra Indonesia, Fakultas Ilmu Budaya, Universitas Jenderal Soedirman, Purwokerto, Indonesia \\ Email: *sulistio.prayogohadi@unsoed.ac.id, usep.muttaqin@unsoed.ac.id, aldi.aditya@unsoed.ac.id
}

\begin{tabular}{l} 
INFORMASI ARTIKEL \\
\hline Article History: \\
Submission: $23-11-2020$ \\
Revised: 08-03-2021 \\
Accepted: 18-03-2021 \\
* Korespondensi: \\
Prayogo Hadi Sulistio \\
sulistio.prayogohadi@ unsoed.ac.id
\end{tabular}

INFORMASI ARTIKEL

Submission: 23-11-2020

Revised: 08-03-2021

* Korespondensi:

sulistio.prayogohadi@unsoed.ac.id

\begin{abstract}
ABSTRAK
Sebagai salah satu media ajar, Mind Master menjadi salah satu alternatif media pembelajaran yang dapat membantu guru dalam proses pembelajaran khususnya dalam digitalisasi mind map dari penjelasan materi. Di SMAN 4 Purwokerto, guru belum maksimal mengeksplorasi media pembelajaran digital sehingga potensi kemampuan siswa dalam berpikir kritis, berkreasi, dan analisis audio-visual belum terpenuhi. Universitas Jenderal Soedirman dapat membantu mitra melalui kegiatan pengenalan dan pelatihan pemanfaatan aplikasi Mind Master kepada masyarakat, khususnya guru-guru SMAN 4 Purwokerto. Kegiatan ini memberikan dampak yang baik kepada guru. Hal tersebut dibuktikan dengan peningkatan kemampuan guru dalam membuat penjelasan materi yang diajarkan menggunakan Mind master yang sebelumnya guru hanya cenderung membuat mind map secara konvensional. Lebih jauh lagi, guru juga memberikan komentar bahwa siswa menunjukkan antusiasme yang meningkat dalam proses pembelajaran karena materi yang dijelaskan menggunakan Mind Master. Selain itu, hasil kuesioner menunjukkan kepuasan guru terhadap kegiatan pengabdian kepada masyarakat ini yang turut berkontribusi pada peningkatan kualitas proses pembelajaran di sekolah.
\end{abstract}

Kata Kunci: Digital mind map, mind master, proses pembelajaran

TRAINING ON THE USE OF MIND MASTER SOFTWARE IN IMPROVING THE QUALITY OF LEARNING FOR TEACHERS AT SMAN 4 PURWOKERTO

\begin{tabular}{l} 
ABSTRACT \\
As one of the teaching media, Mind Master is an alternative learning \\
media that can help teachers in the learning process, especially in \\
digitizing mind map from material being explained. At SMAN 4 \\
Purwokerto, teachers have not optimally explored digital learning \\
media so that the potential for students' abilities in critical thinking, \\
creation, and audio-visual analysis has not been fulfilled. Jenderal \\
Soedirman University can help partners through introductory activities \\
and training on the use of the Mind master application to the public, \\
especially teachers of SMAN 4 Purwokerto. This activity has a good \\
impact on teachers. It is proven by the increase in the ability of \\
teachers to make explanations of the material taught using the Mind \\
Master, where previously teachers only tended to make conventional \\
mind map. Furthermore, the teachers also commented that students \\
showed increased enthusiasm for the learning process because the \\
\hline
\end{tabular} 
material explained used Mind Master. In addition, the results of the questionnaire showed teacher satisfaction with these community service activities which contributed to improving the quality of the learning process in schools.

Keywords: Digital mind map, mind master, learning process

\section{PENDAHULUAN}

Perkembangan teknologi membuat terbukanya eksplorasi teknik-teknik baru, baik dalam kehidupan maupun dalam pembelajaran[1]. Eksplorasi tersebut juga membuat agen-agen dunia pendidikan harus menyesuaikan diri agar output (lulusan) dapat menyesuaikan diri dengan tantangan di dunia luar. Oleh karena itu, guru di masa modern ini harus bisa beradaptasi untuk menggunakan teknologi dalam proses belajar dan mengajar di ruang kelas. Teknologi bisa menjadi alat bantu yang memudahkan para siswa membentuk pemahaman mengenai suatu materi ajar[2].

Pemerintah sudah menyadari hal tersebut. Kementerian Pendidikan dan Kebudayaan sudah merumuskan beberapa indikator profesionalitas guru, salah satunya adalah guru dituntut mampu menggunakan alat bantu audio-visual dalam kegiatan belajar-mengajar. Alat bantu yang tersedia sangat banyak[3]. Guru dapat memilih metode, teknik, alat, atau teknologi yang paling cocok untuk kebutuhannya. Jadi, penting bagi guru untuk mengetahui ragam alat bantu yang tersedia agar guru dapat mengembangkan sendiri teknik mengajarnya[4]. Agar dapat menjelaskan materi ajar dengan baik sehingga siswa dapat dengan mudah memahami, guru bisa menggunakan mind map. Pada dasarnya, mind map adalah gabungan informasi yang diambil dari beberapa sumber dan dijadikan satu dengan menuliskan kata kunci saja [5].

Dari satu kata kunci guru dapat mengeksplorasi hubungan-hubungan dengan konsep lainnya dalam diagram sehingga siswa dapat memahami struktur, mengingat, dan menganalisis komponenkomponennya sehingga pembelajaran bersifat mendalam, tidak hanya mencakup permukaan konsep[6]. Penelitian sebelumnya dalam pengujian teknik mind mapping menyimpulkan bahwa, meski beberapa topik sains tidak cocok dengan teknik tersebut, mind mapping dapat membangun pemahaman sains dan teknologi serta membantu siswa dalam taraf pembelajaran tertentu[7]. Awalnya, mind map hanya konsep yang ditulis secara konvensional di atas bidang datar, seperti kertas atau papan tulis. Kini, mind mapping dapat dilakukan dengan komputer. berubah menjadi digital. Perkembangan media mind mapping ini, dari analog ke komputer, memiliki beberapa keunggulan, antara lain mendukung kolaborasi secara real-time, memiliki mode penyimpanan yang bisa diakses kapan saja dan menjadikan kegiatan presentasi lebih dinamis[8].

Sudah tersedia beberapa program mind mapping yang bisa dipakai untuk pembelajaran di kelas, misalnya MindManager dan Inspiration. Keduanya sudah diuji dan perangkat Inspiration membuat pembelajaran lewat concept mapping (peta konsep) menjadi lebih bermanfaat dan seru[9]. Perangkat lunak lain yang bisa digunakan adalah Mind Master. Perangkat lunak ini gratis untuk diunduh dan dipakai. Oleh karena itu, guru bisa mudah menggunakan mind map dalam pengajarannya.

Berdasarkan hasil observasi dan wawancara dengan Kepala Sekolah SMAN 4 Purwokerto, para guru SMAN 4 tergolong jarang memakai mind map sebagai alat bantu dalam mengajar, terlebih lagi digital mind map. Mereka ingin para siswa mampu memahami materi yang disampaikan oleh guru dengan baik dan juga tidak membosankan. Atas masalah tersebut, Universitas Jenderal Soedirman dapat membantu mitra melalui kegiatan pengenalan dan pelatihan pemanfaatan aplikasi mind mapping kepada masyarakat, khususnya guru-guru SMAN 4 Purwokerto. Melalui kegiatan ini diharapkan guruguru di SMAN 4 Purwokerto mampu membuat digital mind map yang menarik sebagai alat bantu mengajar mereka menggunakan Mind Master[10]. 
Berdasarkan hasil analisis situasi, solusi yang ditawarkan dalam pengabdian kepada masyarakat program penerapan IPTEK ini adalah pelatihan penggunaan software Mind Master dalam menyusun bahan ajar berbasis mind map[11]. Program pelatihan ini menjadi sebuah jalan untuk meningkatkan kualitas pembelajaran di kelas yang pada awalnya cenderung monoton menjadi lebih menarik dan kreatif. Hal ini juga diharapkan dapat meningkatkan antusias belajar para siswa di zaman digital ini, karena pembuatan bahan ajar dalam program ini berbasis digital. Hal ini sangat diperlukan sehingga para guru bisa menyesuaikan gaya mengajar mereka dengan perkembangan zaman[12].

\section{METODE}

Kegiatan pengabdian kepada masyarakat ini dilaksanakan dari bulan April sampai Agustus. Kegiatan ini berlangsung di SMAN 4 Purwokerto dengan alamat Jl. Overste Isdiman, Jatiwinangun, Purwokerto Lor, Kec. Purwokerto Tim, Kabupaten Banyumas, Jawa Tengah 53114.

Sasaran pengabdian ini adalah para guru SMAN 4 Purwokerto. Terdapat sekitar 50 guru di sekolah tersebut. Mereka semua diikutsertakan dalam pelatihan ini karena pentingnya penguasaan kemampuan dalam penyusunan bahan ajar yang menarik serta dapat memicu para siswa untuk berpikir kritis dan kreatif dalam kegiatan pembelajarannya. Para guru tersebut diikutsertakan karena berdasar dari observasi awal bahwa mereka belum menguasai pembuatan bahan ajar yang berbasis digital mind mapping.

Metode pelaksanaan pengabdian kepada masyarakat ini adalah ceramah, Focus Group Discussion, dan workshop terkait dengan penggunaan digital mind map dalam proses pembelajaran serta praktik yang bisa dilakukan guru ketika pelatihan untuk membiasakan diri dalam menggunakan software Mind Master[13]. Terdapat empat langkah utama yang dilakukan yaitu: langkah pertama meliputi greeting, perkenalan, menjelaskan tujuan pelatihan dan memberikan panduan dalam menggunakan Mind Master, dan mengunduh software Mind Master dan memasang ke dalam laptop. Langkah kedua adalah menjelaskan penggunaan fitur yang ada pada Mind Master dalam membuat digital mind mapping, membuat contoh digital mind map menggunakan Mind Master, menyimpan hasil digital mind mapping di dalam komputer atau laptop. Langkah ketiga adalah meminta para guru untuk melakukan praktik membuat digital mind map menggunakan Mind Master, mendampingi guru dalam menggunakan fitur sesuai dengan kebutuhan dan tema dari mind map yang dibuah, menyelesaikan pembuatan digital mind map sesuai dengan tema pembelajaran. Langkah keempat adalah meminta guru untuk mempresentasikan digital mind map yang mereka buat, meminta guru untuk mempraktekan pembuatan digital mind map dalam kelas, mengevaluasi kegiatan.

\section{HASIL DAN PEMBAHASAN}

Pelatihan penggunaan aplikasi mind mapping digital ini dapat dikatakan berhasil apabila guru dapat menggunakan dan mengembangkan pemakaian aplikasi ini dalam pengajaran di kelas[14]. Aplikasi ini diharapkan mampu menjadi sarana pemecahan konsep-konsep rumit yang diajarkan guru di depan siswa. Setelah melakukan pelatihan, berupa presentasi dan pembimbingan, para guru diminta untuk memberikan umpan balik untuk mengevaluasi kegiatan dan penggunaan aplikasi tersebut.

Pelaksanaan pelatihan ini terbuka bagi guru dari bidang studi apa pun. Namun, meski aplikasi ini idealnya dapat digunakan di tiap mata pelajaran, pelatihan dilaksanakan pada 20 orang peserta, dengan sebagian besar peserta adalah guru pengampu mata pelajaran bahasa. Meski begitu, contoh yang diberikan dalam presentasi adalah contoh tematik sehingga penyampaian materi akan bersifat interdisipliner sehingga relevan dengan pengalaman mengajar para guru dari berbagai bidang studi.

Kegiatan pelatihan dilakukan di ruangan laboratorium komputer SMAN 4 Purwokerto. Karena kondisi dan situasi terkait wabah COVID-19, pelatihan ini dilakukan dengan memperhatikan protokol kesehatan di SMAN 4 purwokerto. Pelatihan diawali dengan presentasi untuk memaparkan dasardasar dan menanamkan alasan penggunaan aplikasi mind mapping digital ini. Para guru diberikan 
deskripsi mengenai kelebihan dan kekurangan dalam penggunaan mind mapping, baik secara konvensional maupun digital[15]. Deskripsi mengenai produk-produk piranti lunak mind mapping yang tersedia dan terjangkau juga diinformasikan kepada mereka. Dalam presentasi, diberikan alasan penggunaan piranti lunak Mind Master, yaitu murah dan terjangkau.

Aplikasi Mind Master yang digunakan dalam pelatihan ini disediakan dalam bentuk installer aplikasi yang dibagikan lewat Google Drive. Para guru dibimbing untuk dapat memasang aplikasi tersebut pada komputer mereka. Kendala yang dihadapi dalam pemasangan atau instalasi aplikasi adalah tidak meratanya literasi komputer tiap guru sehingga beberapa guru memerlukan pengarahan yang telaten dan dekat agar bisa melakukan instalasi dengan lancar.

Setelah melakukan instalasi Mind Master di komputer mereka, guru dibimbing untuk membuat pemetaan konsep. Arahan diberikan lewat presentasi yang ditampilkan lewat Google Meet dengan memberikan langkah demi langkah penggunaan aplikasi Mind Master tersebut. Guru diperkenalkan pada tiap fungsi tombol dan fitur yang ada dalam aplikasi. Contoh tema atau topik yang diberikan adalah topik yang sangat umum, yaitu tumbuhan, untuk kemudian dieksplorasi ke konsep-konsep yang lebih khusus. Dengan begitu, para guru bisa mengaitkan topik pilihan mereka dengan materi pelajaran yang akan disampaikan di depan siswa. Pada akhirnya, contoh yang diberikan tampak pada tampilan gambar 1.

Sebagian kendala-kendala yang ditemukan dalam pengarahan penggunaan aplikasi menyangkut kendala teknis, misalnya putusnya koneksi internet di tengah presentasi atau tata suara yang berdengung atau tidak jelas. Meskipun begitu, kendala-kendala teknis seperti itu sudah diantisipasi sejak perencanaan pelatihan sehingga sudah tersedia prosedur untuk mengatasinya. Kendala lainnya adalah adanya guru yang tidak terlalu familiar dalam menggunakan komputer sehingga arahan-arahan teknis yang biasanya memakai istilah-istilah teknologi komputer membutuhkan pengulangan hingga mereka memahaminya. Arahan-arahan tersebut sebenarnya akan lebih efektif jika ditunjukkan atau disampaikan secara langsung dan dekat dengan mereka, tetapi dalam situasi wabah COVID-19, penyampaian arahan hanya terbatas pada jarak tertentu. Meski menemui kendala-kendala tersebut selama presentasi, para guru tampak bersemangat dalam mencoba menggunakan aplikasi sesuai arahan dari pelatih.

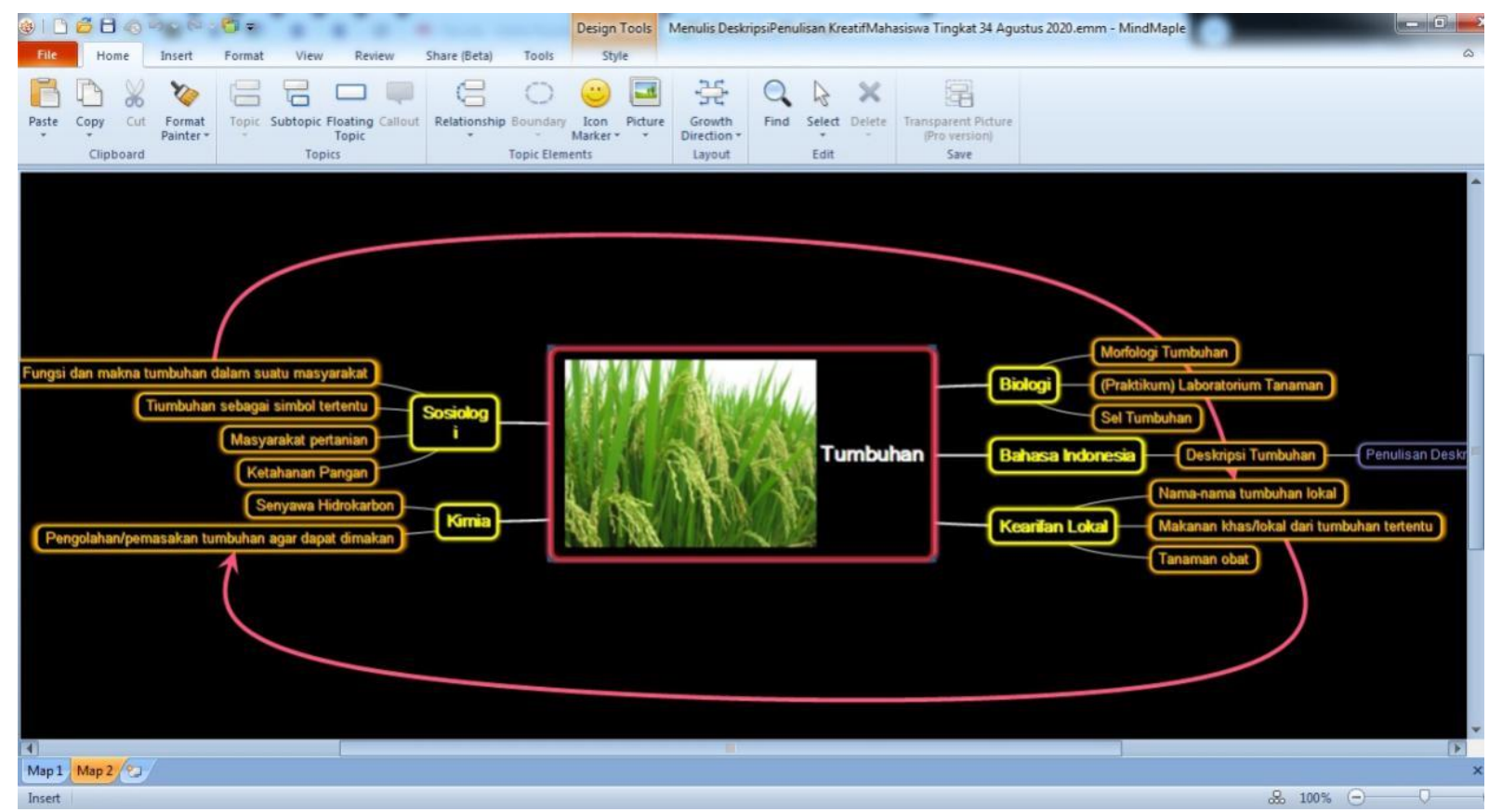

Gambar 1. Contoh Digital Mind Map berjudul "Tumbuhan”. 
Setelah mendapat pelatihan berupa presentasi dan pengarahan penggunaan aplikasi mind mapping digital, para guru diberikan waktu pembimbingan. Selama masa pembimbingan, para guru bisa mencoba menggunakan aplikasi tersebut dalam kegiatan mengajar mereka sehari-hari. Pembimbingan dilakukan lewat grup Whatsapp yang dibuat khusus. Di situ, tanya jawab yang terjadi sebagian besar menyinggung cara mengoperasikan aplikasi Mind Master.

Kegiatan pengabdian kepada masyarakat ini berdampak positif kepada seluruh peserta yang mengikuti kegiatan ini. Adapun perubahan tersebut terangkum pada tabel 1.

Tabel 1. Perubahan yang sebelum dan sesudah kegiatan Pengabdian kepada Masyarakat.

\begin{tabular}{lll}
\hline No. & Keadaan sebelum diadakan kegiatan PkM & Keadaan setelah diadakan kegiatan PkM \\
\hline 1. & $\begin{array}{l}\text { Guru cenderung memakai mind map secara } \\
\text { konvensional dalam penjelasan materi. }\end{array}$ & $\begin{array}{l}\text { Guru memiliki kemampuan yang baik dalam } \\
\text { membuat penjelasan dari materi yang diajarkan } \\
\text { menggunakan Mind Master. }\end{array}$ \\
2. & $\begin{array}{l}\text { Siswa merasa penjelasan guru membosankan } \\
\text { karena penyampaiannya menggunakan media } \\
\text { konvensional. }\end{array}$ & $\begin{array}{l}\text { Antusiasme siswa meningkat karena guru dalam } \\
\text { penyampaian materi menggunakan Mind } \\
\text { Master. }\end{array}$ \\
\hline
\end{tabular}

Tabel 1 menunjukkan bahwa terjadi perubahan positif yang terjadi pada guru dan siswa. Hal tersebut bisa dilihat bahwa guru memiliki kemampuan yang baik dalam menjelaskan materi menggunakan Mind Master. Peningkatan kemampuan pada guru ini tidak lepas dari proses pendampingan dan pemberian masukan yang berlangsung selama kegiatan pengabdian kepada masyarakat ini. Lebih jauh lagi, siswa merasakan dampak langsung dalam pemakaian Mind Master dalam penjelasan yang disampaikan oleh guru di kelas. Antusiasme siswa dalam mengikuti pembelajaran turut meningkat karena penjelasan yang diberikan guru sangat menarik sehingga yang pada awalnya kegiatan pembelajaran berlangsung membosankan berubah menjadi interaktif.

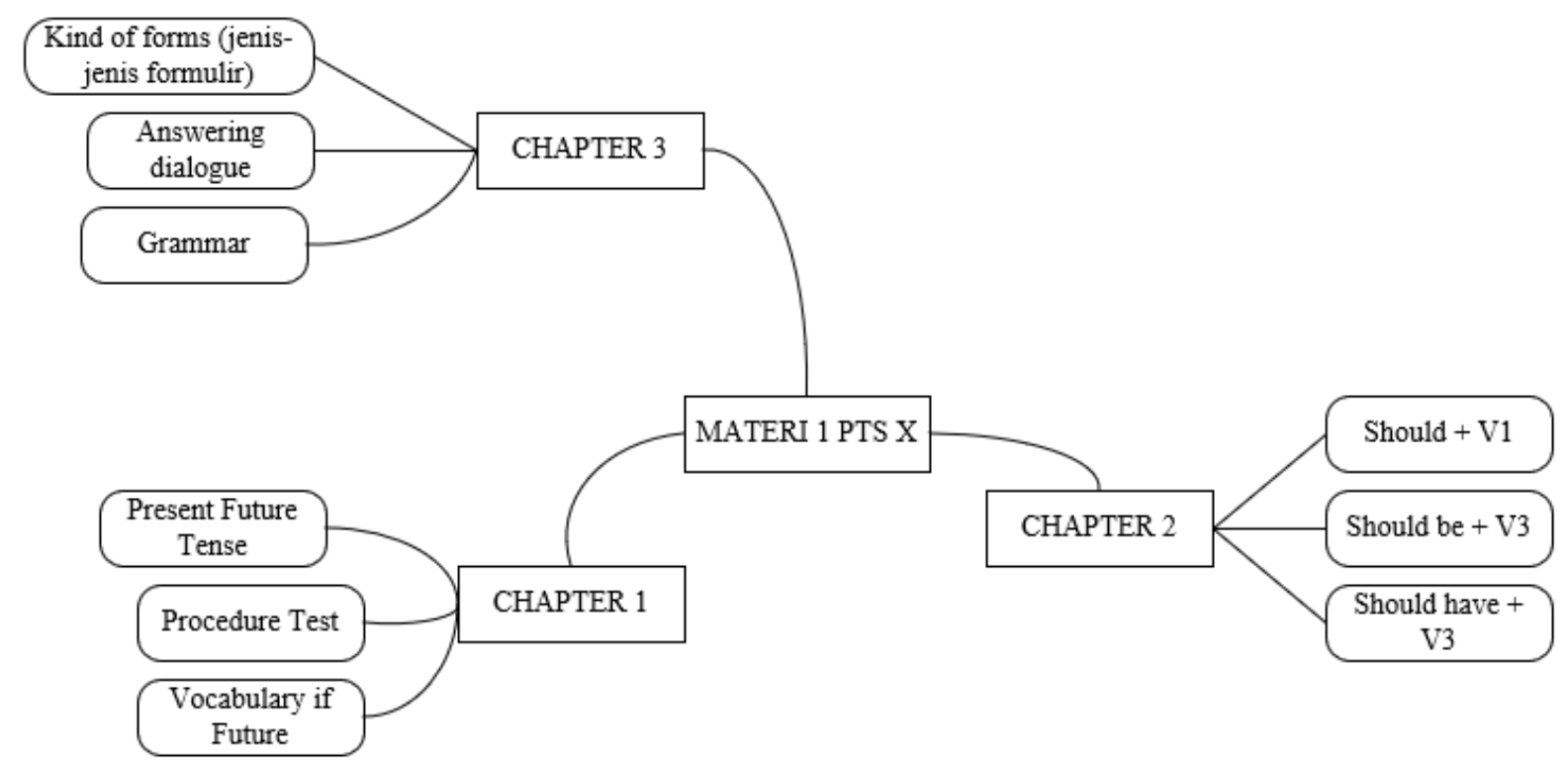

Gambar 2. Contoh 1 Digital Mind Map yang dibuat oleh Guru.

Di penghujung periode pembimbingan pemakaian aplikasi Mind Master, kami melakukan evaluasi untuk mengukur tingkat ketertarikan dan kemungkinan aplikasi ini digunakan dalam tugas sehari-hari mereka. Para guru peserta pelatihan diminta untuk mengisi kuesioner yang disediakan dengan penilaian skala Likert, yaitu dengan rentang nilai 1 untuk penilaian rendah atau sangat tidak puas hingga nilai 5 untuk penilaian tinggi atau sangat puas. Poin penilaian yang didapatkan dari para guru kemudian dihitung reratanya dan dari situ bisa ditentukan tingkat kepuasan para guru dengan 
skala $0-5$, yaitu sangat tidak puas (nilai rerata $0-1.25)$, tidak puas $(1.25-2.5)$, puas $(2.5-3.75)$ dan sangat puas (3.75-5). Ada 13 orang guru, atau 65\% dari jumlah peserta pelatihan, yang mengisi kuesioner evaluasi. Dalam kuesioner, dapat diketahui bahwa pelatihan ini membuat para guru sangat tertarik menggunakan aplikasi Mind Master dalam kegiatan sehari-hari (dengan nilai 4.6). Aplikasi ini juga dirasa sangat mudah digunakan (dengan nilai 4.2) serta dirasa sangat membantu tugas mengajar para guru (dengan nilai 4.2). Sebanyak 11 dari 13 guru (atau 84\%) yang dievaluasi menyatakan telah menggunakan aplikasi pemetaan pikiran dalam kegiatan mengajar mereka sehari-hari. Berikut ini adalah contoh materi yang mereka sampaikan dalam kelas dengan menggunakan aplikasi Mind Master yang dijelaskan pada gambar 2 .

Berikut ini adalah contoh yang dibuat oleh Guru Bahasa Inggris di SMAN 4 Purwokerto. Materi tersebut dipecah dari materi besar PTS X. Pembagian materi didasari oleh pola kalimat yang akan dipelajari siswa. Guru baru memulai memecah materi tentang pola kalimat yang akan dipelajari. Pola tersebut akan dilanjutkan dengan pemberian formula kalimat dan kalimat contoh sesuai dengan tenses atau aturan kalimat yang sedang dipelajari.

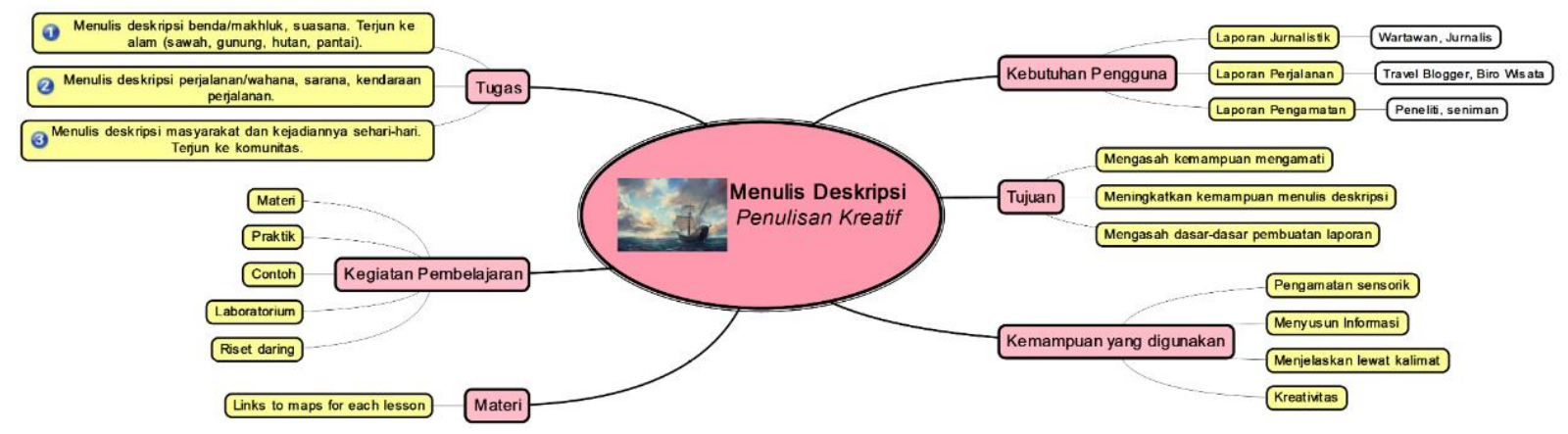

Gambar 3. Contoh 2 Digital Mind Map yang dibuat oleh Guru.

Berbeda dengan contoh sebelumnya yang dibuat oleh Guru Bahasa Inggris, contoh mind map kali ini dibuat oleh Guru Bahasa Indonesia yang membahas tentang "Menulis Deskripsi". Guru tersebut menjelaskan materi mulai dari tujuan pembelajaran sampai memecah materi dari penulisan deskripsi ini. Terlihat, guru memainkan warna untuk membuat pembeda antara topik, sub topic dan bagian terkecil dari materi yang dijelaskan. Jelas sekali, usaha guru untuk menangkap perhatian siswa namun tidak meninggalkan esensi keilmuan dari materi yang dibawakan.

Hasil yang dicapai dalam pelatihan ini adalah (1) guru-guru SMAN 4 Purwokerto telah mengetahui manfaat metode pemetaan pikiran sebagai alat bantu ajar, (2) para guru telah mengenali aplikasi yang dapat dipakai dalam memetakan pikiran sehingga mereka dapat mengembangkan metode mengajar yang lebih efektif dan efisien, dan (3) para guru telah memahami cara menggunakan metode pemetaan pikiran, yaitu Mind Master. Saran yang dapat diusulkan adalah (1) para guru hendaknya menggunakan aplikasi ini terus-menerus untuk mengeksplorasi dan mengembangkan penggunaannya dalam kegiatan belajar dan mengajar dan (2) diperlukan kesinambungan dan keberlanjutan program pelatihan penggunaan aplikasi pemetaan pikiran untuk memperdalam pemanfaatan metode ini.

\section{SIMPULAN}

Kegiatan pengabdian kepada masyarakat yang dilakukan di SMAN 4 Purwokerto memberikan pengaruh positif dalam peningkatan kemampuan guru dalam melakukan aktivitas pengajaran di kelas khususnya menggunakan software Mind Master. Hal ini tertentu berdampak positif dalam proses pembelajaran khususnya bagi siswa agar mereka bisa belajar dengan metode yang tidak monoton. Selain itu, kegiatan ini juga secara langsung memberikan dukungan dalam program sekolah khususnya 
dalam peningkatan kompetensi guru dalam pengajaran. Kegiatan peningkatan kompetensi guru tentu saja tidak boleh berhenti di satu kegiatan saja. Untuk peningkatan kemampuan guru dalam pengajaran, tentu banyak cara yang bisa dilakukan salah satunya dengan memberikan pelatihan pengajaran dengan metode tertentu. Selain itu, para guru juga terus dilibatkan dalam kegiatan diskusi akademik untuk melakukan sosialisasi dan berbagi cerita kendala dalam pembelajaran dan secara bersama mencari solusi konkret yang bisa digunakan untuk mengatasi permasalahan yang ada. Hal ini tentu bertujuan utama untuk meningkatkan kualitas pembelajaran di ruang kelas dan pada akhirnya meningkatkan kualitas sekolah.

\section{UCAPAN TERIMA KASIH}

Tim pengabdian kepada masyarakat mengucapkan terima kasih yang sebanyak-banyaknya kepada Lembaga Penelitian dan Pengabdian Masyarakat Universitas Jenderal Soedirman yang telah mendukung dan mendanai kegiatan pengabdian ini. Kegiatan ini tentunya tidak akan terselenggara tanpa dukungan dari LPPM Unsoed. Tim juga memberikan penghargaan yang setinggi-tingginya kepada pihak sekolah SMA Negeri 4 Purwokerto yang telah menjadi mitra dan terlibat dalam kegiatan pengabdian kepada masyarakat ini.

\section{DAFTAR PUSTAKA}

[1] M. Zamroni, "Perkembangan Teknologi Komunikasi Dan Dampaknya Terhadap Kehidupan," J. Pendidik., vol. X, no. 2, pp. 195-211, 2017.

[2] R. G. Muir-Herzig, "Technology and its impact in the classroom," Comput. Educ., vol. 42, no. 2, pp. 111-131, 2004.

[3] P. Pendidikan, "Pedoman Pelaksanaan Pendidikan," p. 224, 2011.

[4] Teni Nurrita, "Kata Kunci :Pengembangan media pembelajaran untuk meningkatkan hasil belajar siswa," J. misykat, vol. 03, no. 01, p. 171, 2018.

[5] S. Edwards and N. Cooper, "Mind mapping as a teaching resource," Clin. Teach., vol. 7, no. 4, pp. 236-239, 2010.

[6] M. Davies, "Concept mapping, mind mapping and argument mapping: What are the differences and do they matter?," High. Educ., vol. 62, no. 3, pp. 279-301, 2011.

[7] E. Evrekli, A. G. Balim, and D. Inel, "Mind mapping applications in special teaching methods courses for science teacher candidates and teacher candidates' opinions concerning the applications," Procedia - Soc. Behav. Sci., vol. 1, no. 1, pp. 2274-2279, 2009.

[8] H. Lin and H. Faste, "Digital mind mapping: Innovations for real-time collaborative thinking," Conf. Hum. Factors Comput. Syst. - Proc., pp. 2137-2142, 2011.

[9] A. G. Balim, "Use of technology-assisted techniques of mind mapping and concept mapping in science education: a constructivist study," Irish Educ. Stud., vol. 32, no. 4, pp. 437-456, 2013.

[10] A. Karim, "Efektivitas Penggunaan Metode Mind Map Pada Pelatihan Pengembangan Penguasaan Materi Pembelajaran,” IJTIMAIYA J. Soc. Sci. Teach., vol. 1, no. 1, 2018.

[11] F. Firmansyah, R. AR, and D. E. Amrina, "Pelatihan Pembuatan Bahan Ajar Menggunakan Aplikasi Mind Map Bagi Guru Smp 5 Rambang Dangku Muara Enim," J. PROFIT Kaji. Pendidik. Ekon. dan Ilmu Ekon., vol. 7, no. 1, pp. 84-94, 2020.

[12] Efendi, "Revolusi Pembelajaran Berbasis Digital (Penggunaan Animasi Digital Pada Start Up Sebagai Metode Pembelajaran Siswa Belajar Aktif)," Habitus J. Pendidikan, Sosiologi, dan Antropol., vol. 2, no. 2, pp. 173-182, 2018.

[13] . Y. and I. Asto B, "Penerapan Strategi Belajar Peta Konsep (Mind Mapping) Untuk Meningkatkan Hasil Belajar Siswa Pada Standar Kompetensi Menerapkan Dasar-Dasar Elektronika Digital Di SMKN 1 Driyorejo," J. Pendidik. Tek. Elektro, vol. 3, no. 1, pp. 133140, 2013. 
Pembelajaran Bagi Guru Di Sman 4 Purwokerto

[14] N. Amanda, F. Reffiane, and P. Arisyanto, "Pengembangan Media Budel (Buku Berjendela) pada Tema Keluargaku,” J. Penelit. dan Pengemb. Pendidik., vol. 3, no. 2, p. 97, 2019.

[15] V. P. Santi, C. H. Abdat, and U. Makhmudah, "Pengembangan Panduan Mind Mapping untuk Meningkatkan Keterampilan Belajar," Cons. J. Progr. Stud. Bimbing. dan Konseling, vol. 5, no. 2, 2017. 